\title{
Managing the Product-Counterfeiting Problem with a Blockchain-Supported E-Commerce Platform
}

\author{
Ji Jiang * and Jin Chen
}

Citation: Jiang, J.; Chen, J. Managing the Product-Counterfeiting Problem with a Blockchain-Supported E-Commerce Platform. Sustainability 2021, 13, 6016. https://doi.org/ $10.3390 /$ su13116016

Academic Editor: Sungyong Choi

Received: 13 April 2021

Accepted: 20 May 2021

Published: 27 May 2021

Publisher's Note: MDPI stays neutral with regard to jurisdictional claims in published maps and institutional affiliations.

Copyright: (C) 2021 by the authors Licensee MDPI, Basel, Switzerland. This article is an open access article distributed under the terms and conditions of the Creative Commons Attribution (CC BY) license (https:// creativecommons.org/licenses/by/ $4.0 /)$.
School of Information Technology and Management, University of International Business and Economics, Beijing 100029, China; chenjin@uibe.edu.cn

* Correspondence: jiangispe@126.com

\begin{abstract}
As a disruptive tool, blockchain technology can eradicate the product-counterfeiting problem in supply chains. However, a blockchain-supported platform charges an operating fee to legitimate manufacturers and retailers for product traceability and authentication. In this study, we employ enterprise profit-driven analytical models using Stackelberg equilibrium theory and highlight the values of blockchain-supported e-commerce platforms in addressing the product-counterfeiting problem. To measure the actual benefits of blockchain technology, we compare the profits of all agents in two different supply chains, traditional and blockchain-supported. Results show that the application of blockchain technology is not always beneficial to manufacturers, retailers, and customers. However, when the manufacturing cost of a legitimate manufacturer is sufficiently high, the manufacturer generates more profits using blockchain technology. Further, for a price-sensitive market, a retailer tends to trade in a blockchain-supported e-commerce platform if the retailer's qualification in the platform is lower than that in a traditional supply chain, and the manufacturing cost of the counterfeit manufacturer in the platform is higher than that in a traditional supply chain.
\end{abstract}

Keywords: blockchain technology; counterfeit product; supply chain; e-commerce platform

\section{Introduction}

Counterfeit products are widespread in many industries, for example, luxury handbags, perfumes, pharmaceutical products, and automotive components [1-5]. The International Chamber of Commerce of Geneva claimed that the total global annual sale of counterfeit products is USD 650 billion [6]. In addition to causing huge revenue losses for legitimate firms, counterfeit products endanger lives, for example, through autoparts of inferior quality, medicines without active ingredients, and toys with toxic constituents [7-12]. Several technologies were proposed to solve the product-counterfeiting problem, such as radio-frequency identification, barcode scanning, and mobile technology [13-16]. However, these technologies are mainly centralized and rely on trusted servers, which are vulnerable to cyberattacks, for example, replay and man-in-the-middle attacks [17,18]. Blockchain technology has emerged as the best candidate to overcome these attacks. It can build a transparent, trustworthy, and secure supply chain that prevents the counterfeiting of products.

Product information is permanently recorded by a blockchain, and cannot be altered, erased, or manipulated [19]. A blockchain is a public decentralized ledger, so historical product information can be freely observed and verified by a retailer. The transparency of the blockchain-supported e-commerce platform allows for a retailer to immediately know whether their goods are qualified; thus, counterfeit products cannot enter the supply chain $[20,21]$. As blockchain technology ensures traceability and transparency, it can provide a trustful trading environment for enterprises in the supply chain; thus, it is an attractive solution for several supply-chain challenges [22-25]. For instance, Saberi and Kouhizadeh investigated how blockchain technology can address and aid supply-chain 
management. The authors proved that the blockchain, as a potentially disruptive technology, can eliminate many potential barriers [26]. Kshetri also showed that the use of blockchain technology can improve the supply chain's transparency and reliability [27]. Furthermore, many famous international companies, such as Amazon, Walmart, and Alibaba, are committed to establishing new blockchain-supported e-commerce platforms [28-30].

Previous studies and real-world examples [26-30] showed that blockchain-supported e-commerce platforms can be used to solve the counterfeit problem. However, few studies built models to evaluate the real effect of blockchain on entities in the supply chain. Blockchain-supported platforms charge an operating fee to legitimate manufacturers and retailers for product traceability and authentication, which means that using the blockchain increases the costs of legitimate firms. In a traditional supply chain, legitimate firms endure loss of income resulting from counterfeit products. In a blockchain-supported supply chain, firms pay an operating fee. The real effect of the blockchain on firms in the supply chain is not clear, so this paper intends to answer the following three questions to evaluate this technology, and provide some light for scholars and practitioners.

1. How can one construct an analytical model for related entities in traditional and blockchain-supported supply chains? What are the optimal decisions for these enterprises when they trade in both supply-chain types?

2. Compared with the traditional supply chain, how does a blockchain-supported ecommerce platform solve the problem of counterfeit products?

3. Blockchain-supported platforms charge the retailer and manufacturer an operating fee for product traceability and authentication. How does this affect the profit of all parties?

To address the above research questions, we constructed models using game theory. Specifically, we built enterprise profit-driven analytical models, one for the traditional supply chain and one for the blockchain-supported supply chain, in which the manufacturer and retailer negotiate using Stackelberg equilibrium theory. For each supply-chain model, we derived the optimal wholesale price set by the manufacturer and the optimal retail price set by the retailer. We calculated the profits of the manufacturers and retailers, and the consumer surplus and social welfare for both supply chains. In a traditional supply chain, counterfeit products negatively affect legitimate manufacturers, retailers, and consumers. A counterfeit manufacturer seizes profit that belongs to a legal firm, and counterfeit products result in the waste of social resources or the endangerment of lives.

To address the problem of counterfeit products, we combined a platform with blockchain technology. In contrast to a traditional supply chain, a blockchain-supported e-commerce platform can correctly record the entire process of raw-material collection, and goods production and transportation; therefore, an illegal manufacturer does not have any opportunity to deliver inferior products to a retailer.

Although the implementation of blockchain technology in a platform can overcome challenges posed by illegal manufacturers, a blockchain-supported platform charges an operating fee to legitimate manufacturers and retailers for product traceability and authentication. Hence, to measure the actual benefits of blockchain technology, we compared the profits of all agents in a traditional supply chain with the profits of those in a blockchainsupported platform. This study aims to build models that precisely evaluate the effect of blockchain technology on all participating entities within a supply chain while addressing the product counterfeiting problem. Given that many e-commerce companies are committed to combining blockchain technology with trading platforms to eliminate moral hazards in practice, this study provides meaningful management advice to all related entities when the manufacturer and retailer trade on an e-commerce platform.

The remainder of this paper is organized as follows. Section 2 presents a literature review. Section 3 builds a model to explore the profits of all entities in the traditional supply chain and a model to explore the profits of all entities in the blockchain-based supply chain. Section 4 compares the two models to show the real effect of blockchain technology on all entities in the supply chain. Section 5 discusses the results of mathematical 
analysis, answers the three questions in Section 1, concludes this study and presents future research directions.

\section{Literature Review}

The literature related to this study can be classified into three categories: platform operations, blockchain technology, and product-counterfeiting problems in supply chain. We review them in the following sections.

\subsection{Platform Operations}

Currently, platform operations are very well established. An e-commerce platform consists of a platform firm and its two-sided market: sellers and buyers. The platform charges an operating fee to buyers and sellers to facilitate interactions, so that the enterprise's supply and demand can be matched [31-33]. With the recent development of small and medium-sized enterprises (SMEs), several e-commerce platforms have emerged to cater to them, which can be classified into three types. The first type includes platforms based on large-scale e-commerce groups, such as Alibaba (Hangzhou, China) and Amazon Business (Washington, DC, USA), which have a large amount of transaction data and enterprise qualification information according to historical transactions among enterprises [34,35]. It is easy for these platforms to correctly evaluate the ability and demand of enterprises with their recorded information, which is the basis of intelligent matching algorithms. This type of e-commerce platform can provide financing and trade management between manufacturers and retailers in the supply chain. For example, Alibaba International Station is an e-commerce platform for cross-border trade that assists firms by precisely matching buyers and sellers, offering credit guarantees, and facilitating transnational supply-chain management. The second type includes platforms based on core enterprises, such as HC GROUP (Huizhou, China) and JD.COM (Beijing, China), which focus on providing trading information and financing support for their upstream manufacturers and downstream retailers [36,37]. In contrast to the first and second platform types, which only provide services to firms in their own supply chain, the third type includes platforms that focus on building a professional trading platform for all firms, such as GlobalSources (Hong Kong, China) and TradeKey (Riyadh, Saudi Arabia) [38-40]. There are many registered enterprises on this type of platform. As the platforms have powerful data-processing and flexible information-retrieval abilities, they can facilitate deals between many manufacturers and retailers.

\subsection{Blockchain Technology}

The blockchain is a distributed ledger that stores data through a chain structure, as shown in Figure 1. It establishes a trusted environment via consensus algorithms, asymmetric encryption, and smart contracts, giving it characteristics of transparency, decentralization, traceability, and anonymity [41-43]. The blockchain is divided into three different application modes, namely, public, private, and consortium, depending on the level of centralization. A blockchain is chosen according to the different requirements of information confidentiality and transparency under different application scenarios. A public blockchain is completely decentralized, in which each node can participate in the process of data verification, storage, and update without the need to gain access from anyone else $[44,45]$. A private blockchain is centralized, and all its related nodes are strictly controlled in specific institutions [46,47]; the central organization is controlled by a limited number of nodes. A consortium blockchain is partially centralized, in which some specific nodes control the consensus process $[48,49]$. Compared with private and public blockchains, the authority of nodes in a consortium blockchain can be flexibly set, and information processing is faster. Thus, consortium blockchains are widely applied. 


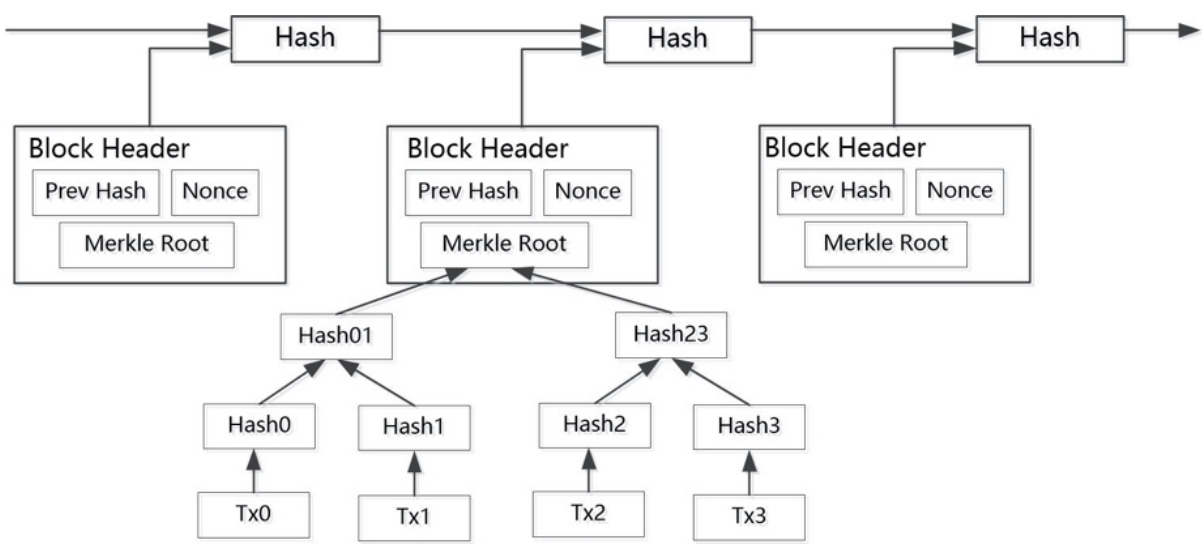

Figure 1. Blockchain structure.

Most existing studies on the blockchain originated from a white paper by Nakamoto, in which the concept of the bitcoin cryptocurrency was first put forward [50]. Currently, blockchain technology could be applied to overcome problems in supply chains. Some studies focused on improving supply-chain finance (SCF). Chen and Cai propose a blockchaindriven platform to solve pain points existing in traditional SCF. They found that this efficient and reliable financing platform for SMEs could reduce financing costs and accelerate cash flows [51]. Du and Chen combined a supply-chain financial platform with blockchain technology to overcome the lack of trust between buyer and seller during a transaction. The study also used homomorphic encryption to ensure the security of sensitive information [52]. Other studies mainly focused on blockchain technology that facilitates the management of supply chains. Choi built a model with consumer utility to explore the values of blockchain-technology-supported platforms for diamond authentication and certification. The study also found that a decrease in blockchain-based diamond authentication and certification costs is beneficial to all parties in the supply chain [53]. Cai and Choi proposed that the adoption of blockchain technology could eradicate the moral-hazard problem under a markdown sponsor contract [54]. Song et al. proposed a new IoT management framework based on blockchain technology to facilitate companies to effectively build a supply chain [55].

\subsection{Product Counterfeiting Problem in Supply Chains}

As is evident from previous studies, the counterfeiting problem in supply chains can be classified into two types. First, customers may choose to buy counterfeit products even though they can differentiate between genuine and fake products, mainly because they are unwilling (or unable) to pay for the more expensive genuine products [56]. Second, the customer cannot distinguish between the two products because the fake product looks identical to the genuine product [57]. Both situations have adverse effects on the legal manufacturer's profit and brand reputation. To highlight the research issues, we focus on the latter situation. Several technologies have been applied to solve the productcounterfeiting problem in the supply chain, such as radio-frequency identification, barcode scanning, and mobile and blockchain technologies. Owing to its rapid development, blockchain technology is the most attractive solution. Alzahrani and Bulusu combined blockchain technology with near-field communication technology to detect counterfeiting attacks [58]. Kumar and Tripathi used blockchain and encrypted quick-response code technology to track whether a drug contained the correct active pharmaceutical ingredients in the manufacturing process [59]. Modgil and Sonwaney proposed that the application of blockchain technology could establish an effective mechanism for the identification of counterfeit products [60].

Past research investigated whether the combination of blockchain technology and an e-commerce platform could eradicate the product-counterfeiting problem. However, this study establishes different models to explore the blockchain-supported e-commerce 
platform's effect on all entities in the supply chain. The literature suggests that previous studies could not build formal analytical models to explore this aspect.

\section{Methodology}

To evaluate the effect of the blockchain, we constructed models according to game theory. Specifically, we built enterprise profit-driven analytical models, one for the traditional supply chain and one for the blockchain-supported supply chain, in which the manufacturer and retailer negotiate using Stackelberg equilibrium theory. For each supply-chain model, we derived the optimal wholesale price set by the manufacturer and the optimal retail price set by the retailer. We calculated the manufacturers and retailers' profits, and the consumer surplus and social welfare for both supply chains.

\subsection{Transactions in Traditional Supply Chains}

In a traditional supply chain, product-counterfeiting problems are severe. When fake goods are almost identical in appearance to that of their genuine counterparts, retailers find difficulty in distinguishing between both products. For this reason, many illegal enterprises produce counterfeit products to seize more profits; this harms the profits of all legitimate enterprises and the interests of customers. More importantly, it affects the stable development of a supply chain.

In this section, we build a model to explore the profits of all entities in an insecure trading environment where counterfeit manufacturers could confuse retailers and consumers. Consider a supply chain that includes a legitimate manufacturer, a counterfeit manufacturer (a manufacturer who sells counterfeit products), and $\mathrm{K}$ retailers, where $\mathrm{K}>1$. For retailer $i$, ordering quantity $d_{i}$ depends on its own market, which includes $n_{i}$ customers willing to buy this product and valuation $v_{i}$ of the product for customers, in which $v_{i}$ follows a distribution $f_{i}($.$) ; we consider f_{i}($.$) to be uniform distribution in the range of 0-1$. Customers' purchase intentions are related to retailer's qualifications, such as company size, brand effect, and service levels, which are denoted by $\phi_{i}$, where $\phi_{i}>0$. Retail price is denoted by $p_{i}$. Thus, product demand $d_{i}$ of retailer $i$ is given as follows:

$$
d_{i}=n_{i} \int_{p_{i}-\phi_{i}}^{1} f\left(v_{i}\right) d v_{i}=n_{i}\left(1-p_{i}+\phi_{i}\right)
$$

$d$ is the product demand of all the retailers and can be expressed as follows:

$$
d=\sum_{i=1}^{K} d_{i}
$$

Retailer $i$ obtains the commodity from the legitimate manufacturer at unit wholesale price $w_{i}$. To deceive the retailer, the counterfeit manufacturer tends to be consistent with the legitimate manufacturer; thus, retailer $i$ obtains the commodity from the counterfeit manufacturer at the same wholesale price $w_{i}$. Therefore, the retailer is unable to distinguish between the legitimate and the counterfeit manufacturer. The legitimate manufacturer produces the commodity at a unit cost $c_{1}$, while the counterfeit manufacturer produces the commodity at a unit cost $c_{2}$. The costs of the counterfeit manufacturer are lower than those of the legitimate manufacturer; therefore, $c_{1}>c_{2}$. To avoid trivial cases, we assume $p_{i}>w_{i}>c_{1}>c_{2}$. For retailer $i$, the number of products provided by the legitimate manufacturer is $d_{1 i}$, while the number of products provided by the counterfeit manufacturer is $d_{2 i}$. We assume that the market clears; thus, $d_{i}=d_{1 i}+d_{2 i}$. The profit functions of retailer $i$, the legitimate manufacturer, are denoted by LM; those of the counterfeit manufacturer, denoted by $\mathrm{CM}$, are shown below, respectively. Superscript $\mathrm{T}$ refers to the functions related to the traditional supply chain.

$$
\pi_{i}^{(T)}\left(p_{i}\right)=\left(p_{i}-w_{i}\right) d_{i}=\left(p_{i}-w_{i}\right) n_{i}\left(1-p_{i}+\phi_{i}\right),
$$




$$
\begin{aligned}
& \pi_{L M}^{(T)}\left(w_{i}, d_{1 i}\right)=\sum_{i=1}^{K}\left(w_{i}-c_{1}\right) d_{1 i}, \\
& \pi_{C M}^{(T)}\left(w_{i}, d_{2 i}\right)=\sum_{i=1}^{K}\left(w_{i}-c_{2}\right) d_{2 i} .
\end{aligned}
$$

$d \pi_{i}^{(T)}\left(p_{i}\right) / d p_{i}=n_{i}\left(1-2 p_{i}+\phi_{i}+w_{i}\right)$ and $d^{2} \pi_{i}^{(T)}\left(p_{i}\right) / d p_{i}{ }^{2}=-2 n_{i}<0$. Thus, $\pi_{i}^{(T)}\left(p_{i}\right)$ is a concave function of $p_{i}$. For a certain $w_{i}$, the optimal retail price for retailer $i$ is given by first-order condition

$$
\stackrel{*}{p_{i}} \mid w_{i}=\underset{p_{i}}{\arg }\left\{\frac{d \pi_{i}^{(T)}\left(p_{i}\right)}{d p_{i}}=0\right\} .
$$

Therefore, we have

$$
\stackrel{*}{p_{i}} \mid w_{i}=\left(1+\phi_{i}+w_{i}\right) / 2 \text {. }
$$

Substituting (7) into (1), we obtain the product demand of retailer $i$ as follows:

$$
d_{i}\left(\stackrel{*}{p}_{i} \mid w_{i}\right)=n_{i}\left(1-p_{i}+\phi_{i}\right)=\frac{n_{i}}{2}\left(1+\phi_{i}-w_{i}\right) .
$$

According to (8), we further define the profits of the legitimate and counterfeit manufacturers:

$$
\begin{aligned}
& \pi_{L M}^{(T)}\left(d_{1 i}\right)=\sum_{i=1}^{K}\left(w_{i}-c_{1}\right) d_{1 i}=\sum_{i=1}^{K}\left(1+\phi_{i}-\frac{2\left(d_{1 i}+d_{2 i}\right)}{n_{i}}-c_{1}\right) d_{1 i} \\
& \pi_{C M}^{(T)}\left(d_{2 i}\right)=\sum_{i=1}^{K}\left(w_{i}-c_{2}\right) d_{2 i}=\sum_{i=1}^{K}\left(1+\phi_{i}-\frac{2\left(d_{1 i}+d_{2 i}\right)}{n_{i}}-c_{2}\right) d_{2 i} .
\end{aligned}
$$

In the traditional supply chain, we used the Stackelberg model to determine the output and wholesale price of the manufacturer. The legitimate manufacturer is the dominant firm, and thereby sets the wholesale price, and the counterfeit manufacturer is the follower, which optimizes its production according to the dominant firm. It is straightforward to derive that $\pi_{C M}^{(T)}\left(d_{2 i}\right)$ is concave in $d_{2 i}$ and $d^{2} \pi_{C M}^{(T)}\left(d_{2 i}\right) / d d_{2 i}{ }^{2}<0$. Thus, the response function can be expressed as follows:

$$
d_{2 i}=\frac{n_{i}\left(1+\phi_{i}-c_{2}\right)}{4}-\frac{d_{1 i}}{2}
$$

Substituting (11) into (9), the profit function of the legitimate manufacturer is as follows:

$$
\pi_{L M}^{(T)}\left(d_{1 i}\right)=\sum_{i=1}^{K}\left(\frac{1+\phi_{i}+c_{2}}{2}-\frac{d_{1 i}}{n_{i}}-c_{1}\right) d_{1 i} .
$$

To maximize the profit of the manufacturer, we use

$$
\begin{aligned}
& d_{1 i}{ }^{(T)}=\frac{n_{i}\left(1+\phi_{i}+c_{2}-2 c_{1}\right)}{4}, \\
& d_{2 i}{ }^{(T)}=\frac{n_{i}\left(1+\phi_{i}-3 c_{2}+2 c_{1}\right)}{8} .
\end{aligned}
$$

Accordingly, the retailer's retail price, the retailer's product demand, and the manufacturer's wholesale price can be rewritten, respectively, as follows:

$$
p_{i}^{(T)}=\frac{5+5 \phi_{i}+c_{2}+2 c_{1}}{8},
$$




$$
\begin{gathered}
d_{i}^{(T)}=\frac{n_{i}\left(3+3 \phi_{i}-c_{2}-2 c_{1}\right)}{8}, \\
w_{i}^{(T)}=\frac{1+\phi_{i}+c_{2}+2 c_{1}}{4} .
\end{gathered}
$$

Figure 2 shows the typical transactions in a traditional supply chain. Each manufacturer determines the optimal wholesale price to maximize income, while the retailer determines the optimal retail price to maximize income. Lemma 1 illustrates the results.

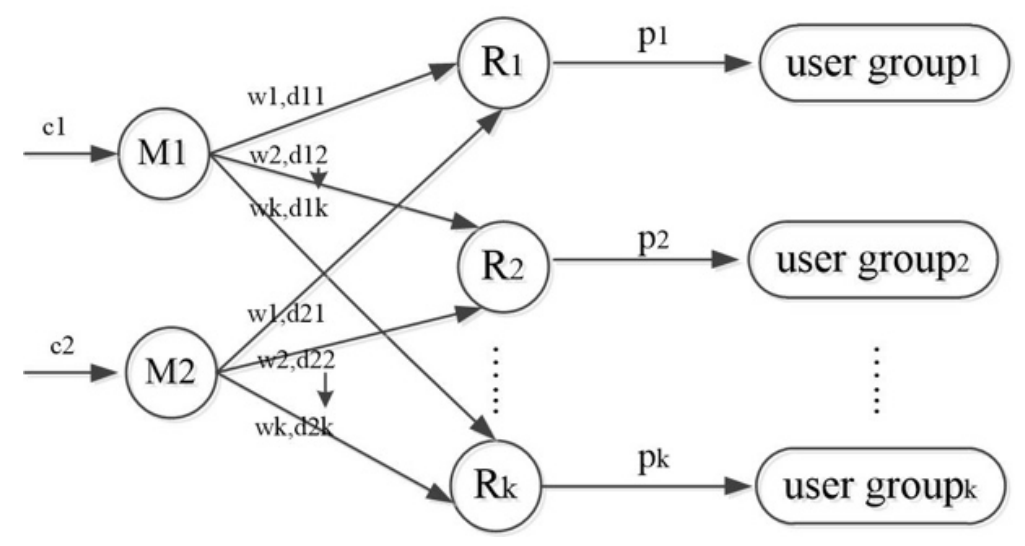

Figure 2. Transactions in traditional supply chains.

Lemma 1. In a traditional supply chain, at the Stackelberg equilibrium, the following statements can be made: (a) the optimal wholesale price of the manufacturer is $w_{i}{ }^{(T)}=\frac{1+\phi_{i}+c_{2}+2 c_{1}}{4}$; (b) from the legitimate manufacturer's perspective, we deduce that the optimal output is $d_{1 i}(T)=$ $\frac{n_{i}\left(1+\phi_{i}+c_{2}-2 c_{1}\right)}{4}$; (c) from the counterfeit manufacturer's perspective, we deduce that the optimal production is $d_{2 i}{ }^{(T)}=\frac{n_{i}\left(1+\phi_{i}-3 c_{2}+2 c_{1}\right)}{8}$; (d) from the retailer's perspective, we deduce the optimal retail price for each unit of product is $p_{i}{ }^{(T)}=\frac{5+5 \phi_{i}+c_{2}+2 c_{1}}{8}$; and (e) the product demand is $d_{i}(T)=\frac{n_{i}\left(3+3 \phi_{i}-c_{2}-2 c_{1}\right)}{8}$.

In addition to the profits of the manufacturers and retailers, we calculate the consumer surplus and social welfare. In the supply chain, consumer surplus is given as follows:

$$
C S^{(T)}=\sum_{i=1}^{K} n_{i} \int_{p_{i}-\phi_{i}}^{1}\left(v_{i}-\left(p_{i}-\phi_{i}\right)\right) f\left(v_{i}\right) d v_{i}=\sum_{i=1}^{K} \frac{n_{i}}{2}\left(1+\phi_{i}-p_{i}\right)^{2}
$$

The definition of social welfare is given as follows:

$$
S W^{(T)}=C S^{(T)}+\pi_{L M}^{(T)}\left(w_{1 i}\right)+\pi_{C M}^{(T)}\left(w_{2 i}\right)+\pi_{R}^{(T)}
$$

The total profit of all retailers in a traditional supply chain is defined as follows:

$$
\pi_{R}{ }^{(T)}=\sum_{i=1}^{K} \pi_{i}^{(T)}
$$

According to the optimal decisions in Lemma 1, we can deduce the retailer's profits, the legitimate manufacturer's profit, the counterfeit manufacturer's profit, consumer surplus, and social welfare, respectively, as follows:

$$
\pi_{R}^{*}(T)=\sum_{i=1}^{K} \frac{n_{i}}{64}\left(3+3 \phi_{i}-c_{2}-2 c_{1}\right)^{2},
$$




$$
\begin{aligned}
& \pi_{L M}^{*}=\sum_{i=1}^{K} \frac{n_{i}}{16}\left(1+\phi_{i}+c_{2}-2 c_{1}\right)^{2}, \\
& \pi_{C M}^{*}(T)=\sum_{i=1}^{K} \frac{n_{i}}{32}\left(1+\phi_{i}-3 c_{2}+2 c_{1}\right)^{2}, \\
& { }^{*} S^{*}(T)=\sum_{i=1}^{K} \frac{n_{i}}{128}\left(3+3 \phi_{i}-c_{2}-2 c_{1}\right)^{2}, \\
& S W^{*}(T)=\pi_{R}^{*}(T)+\pi_{L M}^{(T)}+\pi_{C M}^{(T)}+C S^{(T)} .
\end{aligned}
$$

\subsection{Transactions in a Blockchain-Supported E-Commerce Platform}

The above analysis shows that the product-counterfeiting problem plagues traditional supply chains. This allows for counterfeit manufacturers to seize a large share of profits that belong to legitimate enterprises. To solve this problem, we introduce a blockchainsupported e-commerce platform to support transactions between manufacturers and retailers. The blockchain is a distributed ledger that establishes a trusted environment via consensus algorithms, asymmetric encryption, and smart contracts. Owing to its characteristics of authenticity, traceability, and unforgeability, blockchain technology can solve the product-counterfeiting problem. In contrast to a traditional supply chain, all product information is effectively recorded and can always be verified in the blockchain-supported e-commerce platform; therefore, a counterfeit manufacturer has no access to the supply chain to sell its products.

We assume that the product demand of the retailer in the blockchain-supported supply chain is the same as that in a traditional supply chain. However, the implementation of blockchain technology in a platform is expensive, as it includes the costs of establishing hash tags, the building of blocks, and cryptocurrency settlement. The platform's cost for every transaction is $c_{b l c}$. The retailer and manufacturer must pay operating fees to the platform, denoted by $T_{R}$ and $T_{M}$, respectively. Generally, these fees are fixed and related to the business scales of the retailer and manufacturer, rather than ordering quantity.

The profit function of the retailer, manufacturer, and platform are expressed, respectively, as below. This derivation is like that of the traditional supply chain. Superscript BLC denotes functions related to the blockchain.

$$
\begin{gathered}
\pi_{i}{ }^{(B L C)}=\left(p_{i}{ }^{(B L C)}-w_{i}{ }^{(B L C)}\right) d_{i}{ }^{(B L C)}-T_{R}, \\
\pi_{L M}{ }^{(B L C)}=\sum_{i=1}^{K}\left(w_{i}{ }^{(B L C)}-c_{1}\right) d_{i}{ }^{(B L C)}-K T_{M}, \\
\pi_{P F}{ }^{(B L C)}=\sum_{i=1}^{K}\left(T_{M}+T_{R}-c_{b l c}\right) .
\end{gathered}
$$

Consumer surplus is the same as that in the traditional supply chain, while social welfare can be expressed as follows:

$$
S W^{(B L C)}=C S^{(B L C)}+\pi_{L M}{ }^{(B L C)}+\pi_{R}{ }^{(B L C)}+\pi_{P F}{ }^{(B L C)} .
$$

The total profit of all retailers in the blockchain-supported e-commerce platform is defined as follows:

$$
\pi_{R}{ }^{(B L C)}=\sum_{i=1}^{K} \pi_{i}{ }^{(B L C)}
$$

We can deduce the retail price of the retailer, product demand of the retailer, and wholesale price of the manufacturer in the blockchain-supported e-commerce platform, which are summarized in lemma 2. This approach is like that of a traditional supply chain. 
Lemma 2. In the blockchain-supported e-commerce platform, at the Stackelberg equilibrium, the following statements can be made: (a) from the manufacturer's perspective, the optimal wholesale price of the manufacturer is $w_{i}{ }^{(B L C)}=\frac{1+\phi_{i}+c_{1}}{2},(b)$ from the retailer's perspective, we deduce that the optimal retail price for each unit of product is $p_{i}(B L C)=\frac{3+3 \phi_{i}+c_{1}}{4}$; and (c) product demand is $d_{i}{ }^{(B L C)}=\frac{n_{i}}{4}\left(1+\phi_{i}-c_{1}\right)$.

According to the optimal decisions in Lemma 2, we can deduce the retailer's profits, manufacturer's profit, platform's profit, consumer surplus, and social welfare, respectively, as follows:

$$
\begin{gathered}
\pi_{R}^{\stackrel{*}{(B L C)}}=\sum_{i=1}^{K} \frac{n_{i}}{16}\left(1+\phi_{i}-c_{1}\right)^{2}-K T_{R}, \\
\pi_{L M}^{\stackrel{*}{(B L C)}}=\sum_{i=1}^{K} \frac{n_{i}}{8}\left(1+\phi_{i}-c_{1}\right)^{2}-K T_{M}, \\
\pi_{P F}^{(B L C)}=\sum_{i=1}^{K}\left(T_{R}+T_{M}-c_{b l c}\right) \\
C S^{*(B L C)}=\sum_{i=1}^{K} \frac{n_{i}}{32}\left(1+\phi_{i}-c_{1}\right)^{2}, \\
S W^{(B L C)}=\pi_{R}^{(B L C)}+\pi_{L M}^{(B L C)}+\pi_{P F}^{(B L C)}+C S^{(B L C)} .
\end{gathered}
$$

\subsection{Values of a Blockchain-Supported E-Commerce Platform}

Although the blockchain-supported e-commerce platform can overcome the productcounterfeiting problem, it charges retailers and manufacturers an operating fee for doing so. Thus, to measure the real influence of the e-commerce platform, we deduced the change in profits of all firms, consumer surplus, and social welfare, respectively, as follows:

$$
\begin{gathered}
P M_{M}{ }^{B L C}=\pi_{L M}^{(B L C)}-\pi_{L M}^{*(T)}=\sum_{i=1}^{K} \frac{n_{i}}{8}\left(1+\phi_{i}-c_{1}\right)^{2}-K T_{M}-\sum_{i=1}^{K} \frac{n_{i}}{16}\left(1+\phi_{i}+c_{2}-2 c_{1}\right)^{2}, \\
P M_{R}{ }^{B L C}=\pi_{R}^{(B L C)}-\pi_{R}^{(T)}=\sum_{i=1}^{K} \frac{n_{i}}{16}\left(1+\phi_{i}-c_{1}\right)^{2}-K T_{R}-\sum_{i=1}^{K} \frac{n_{i}}{64}\left(3+3 \phi_{i}-c_{2}-2 c_{1}\right)^{2}, \\
P M_{C S}{ }^{B L C}=C S^{(B L C)}-C S^{(T)}=\sum_{i=1}^{K} \frac{n_{i}}{32}\left(1+\phi_{i}-c_{1}\right)^{2}-\sum_{i=1}^{K} \frac{n_{i}}{128}\left(3+3 \phi_{i}-c_{2}-2 c_{1}\right)^{2}, \\
P M_{S W}^{B L C}=S W^{(B L C)}-S W^{(T)}=P M_{M^{B L C}}{ }^{*} P M_{R}{ }^{B L C}+P M_{C S}{ }^{B L C}+\pi_{P F}{ }^{(B L C)}-\pi_{C M}^{(T)} .
\end{gathered}
$$

$d P M_{M}{ }^{B L C} / d c_{1}<0$ is true, which means that $P M_{M}{ }^{B L C}$ is a monotonically decreasing function of $c_{1}$. Thus, when $c_{1}, c_{2}$, and $\phi_{i}$ meet a certain condition, the change in the profit of the legitimate manufacturer between the traditional and blockchain-supported supply chains is zero. Specifically, when the manufacturing cost of the legitimate manufacturer is sufficiently large, the manufacturer achieves more profits with blockchain technology. For example, in the luxury industry, manufacturers usually invest a considerable workforce and material resources to design new products. However, counterfeit manufacturers can easily imitate these products to obtain illicit earnings, which causes the legitimate manufacturer to suffer huge economic losses and reputational damage. Therefore, it is important for such industries to apply blockchain technology to eliminate counterfeit products.

Moreover, $d P M_{l}{ }^{B L C} / d c_{1}=\sum_{i=1}^{K} A_{l} \cdot n_{i} \cdot\left(1+\phi_{i}-c_{2}\right) ; A_{l}$ is a positive real number for $l \in\{R, C S\}$, which means that $P M_{l}^{B L C}$ is a monotone function of $c_{1}$. If $1+\phi_{i}>c_{2}, P M_{l}{ }^{B L C}$ is a monotonically increasing function of $c_{1}$; otherwise, it is a monotonically decreasing 
function of $c_{1}$. In addition, $d P M_{S W}{ }^{B L C} / d c_{1}=\sum_{i=1}^{K} \frac{n_{i}}{16} \cdot\left(2+2 \phi_{i}+c_{2}-3 c_{1}\right)$, which means that $P M_{S W}{ }^{B L C}$ is a monotonically increasing function of $c_{1}$ when $2+2 \phi_{i}+c_{2}>3 c_{1}$; otherwise, it is a monotonically decreasing function of $c_{1}$. Thus, when $c_{1}, c_{2}$, and $\phi_{i}$ meet a certain condition, the change in the retailer's profit, consumer surplus, and social welfare between the traditional supply chain and the blockchain-supported supply chain is zero. When the manufacturer and retailer trade on the blockchain-supported platform, the platform charges the manufacturer and the retailer an operating fee; the retailer and consumer carry the burden of this cost. From the perspective of social welfare, the fee adds to the profit of the platform and reduces the profit of the illegal manufacturer. This means that the application of blockchain technology is not always beneficial for retailers, customers, and broader society. According to analysis of the change in all agents, the product-counterfeiting problem can be eliminated when the retailer and manufacturer trade on the blockchainsupported e-commerce platform. As blockchain technology's attributes are commonly shared and untampered, its implementation leads to fairness and efficiency for all agents in the supply chain.

To further illustrate the difference between the traditional and blockchain-supported supply chains, we focus on the change in retail price, product demand, and wholesale price. We assume that the market clears; therefore, the product demand of the retailer is in line with the output of the manufacturer. According to the results of Lemmas 1 and 2, we define the expected value of the retail price, product demand, and wholesale price, respectively, as below. To simplify the expression, we define $A=1+\phi_{i}$.

$$
\begin{gathered}
E V_{p_{i}}{ }^{(B L C)}=p_{i}{ }^{(B L C)}-p_{i}{ }^{(T)}=\frac{1+\phi_{i}-c_{2}}{8}, \\
E V_{d_{i}}{ }^{(B L C)}=d_{i}{ }^{(B L C)}-d_{i}{ }^{(T)}=\frac{n_{i}\left(c_{2}-1-\phi_{i}\right)}{8}, \\
E V_{w_{i}}{ }^{(B L C)}=w_{i}{ }^{(B L C)}-w_{i}{ }^{(T)}=\frac{1+\phi_{i}+c_{2}}{4} .
\end{gathered}
$$

Lemma 3 shows the attributes and characteristics of the above equations.

Lemma 3. (a) $E V_{p_{i}}{ }^{(B L C)}=\left(A-c_{2}\right) / 8$, where $i=1, \ldots, k . E V_{p_{i}}{ }^{(B L C)}$ depends on the relationship between $A$ and $c_{2}$. If $A>c_{2}, E V_{p_{i}}{ }^{(B L C)}$ is always positive; otherwise, $E V_{p_{i}}{ }^{(B L C)}$ is negative; (b) $E V_{d_{i}}{ }^{(B L C)}=n_{i}\left(c_{2}-A\right) / 8$, where $i=1, \ldots, k$. If $A>c_{2}, E V_{d_{i}}{ }^{(B L C)}$ is always negative; otherwise, $E V_{p_{i}}{ }^{(B L C)}$ is positive; (c) $E V_{w_{i}}{ }^{(B L C)}=\left(c_{2}+A\right) / 4$, where $i=1, \ldots, k$, and $E V_{w_{i}}(B L C)$ is always positive.

\section{Discussion}

According to our mathematical analysis, the following subsections answer the three questions in Section 1.

4.1. How Can One Construct an Analytical Model for the Related Entities in the Traditional Supply Chain and Blockchain-Supported Supply Chain? What Are the Optimal Decisions for These Enterprises When They Trade in Both Supply Chains?

In our article, we built enterprise profit-driven analytical models, one for the traditional and one for the blockchain-supported supply chain, in which the manufacturer and retailer negotiate using Stackelberg equilibrium theory. We deduced the optimal wholesale price and output of the manufacturer, the optimal retail price, and the product demand of the retailer in both supply chains. In a traditional supply chain, the optimal wholesale price of the manufacturer increases when retailer qualification $\phi_{i}$ and the production cost of the two manufacturers increase. The output of the legitimate manufacturer increases with retailer qualification $\phi_{i}$ and the production cost of the counterfeit manufacturer, while output decreases with its cost. The output of the counterfeit manufacturer has a similar 
result. The retailer's optimal retail price increases in the retailer's qualification and the production cost of the two manufacturers. The product demand of the retailer increases with retailer qualification and decreases with the production cost of the two manufacturers. In the blockchain-supported supply chain, we have similar results with those of the traditional supply chain about the optimal wholesale price, the optimal retail price, and the product demand of the retailer.

Moreover, we also deduced the retailer's profits, the manufacturer's profit, consumer surplus, and social welfare. In a traditional supply chain, the profits of the entities depend on the value of the total market size $N=\sum_{i=1}^{K} n_{i}$, the retailer's qualification $\phi_{i}$, and the manufacturing costs of the two manufacturers $c_{1}$ and $c_{2}$. First, if $N$ or $\phi_{i}$ increases, the profits of all entities increase. Second, the profits of all retailers and consumer surplus decrease with manufacturing $\operatorname{costs} c_{1}$ and $c_{2}$. Third, the profit of the legitimate manufacturer increases with its own manufacturing cost and decreases with the counterfeiter's manufacturing cost. Unlike the traditional supply chain, the counterfeit manufacturer is absent in the blockchain-supported e-commerce platform; therefore, we only have the profits of the legitimate manufacturer, the retailer, and the e-commerce platform. If $N$ or $\phi_{i}$ increases, the retailer's profit, manufacturer's profit, consumer surplus, and social welfare all increase. These results are similar to those of the traditional supply chain.

\subsection{Compared with the Traditional Supply Chain, How does a Blockchain-Supported E-Commerce Platform Solve the Problem of Counterfeit Products?}

To address the problem of counterfeit products, we combined a platform with blockchain technology. The blockchain is a distributed ledger that stores data through a chain structure. It establishes a trusted environment via consensus algorithms, asymmetric encryption, and smart contracts, which gives characteristics of transparency, decentralization, traceability, and anonymity. Product information is permanently recorded by a blockchain, which cannot be altered, erased, or otherwise manipulated, so that historical product information can be freely observed and verified by a retailer. The transparency of blockchain-supported e-commerce platforms allows for a retailer to immediately know whether their goods are qualified; thus, counterfeit products cannot enter the supply chain. In contrast to a traditional supply chain, a blockchain-supported e-commerce platform can correctly record the entire process of raw material collection, and goods production and transportation; therefore, an illegal manufacturer cannot deliver inferior products to a retailer.

\subsection{Blockchain-Supported Platforms Charge the Retailer and Manufacturer an Operating Fee for Product Traceability and Authentication; How Does This Affect the Profit of All Parties?}

To measure the real influence of blockchain technology, we compare the difference of the profits of all firms, consumer surplus, and social welfare in both supply chains. When the manufacturing cost of the legitimate manufacturer is sufficiently large, they achieve more profits with blockchain technology, and when the manufacturer and retailer trade on the blockchain-supported platform, the platform charges them an operating fee; the retailer and consumer carry the burden of this cost. From the perspective of social welfare, the fee adds to the profit of the platform and reduces the profit of the illegal manufacturer. This means that the application of blockchain technology is not always beneficial for retailers, customers, and society.

To further illustrate the difference between the traditional and blockchain-supported supply chains, we also focus on the change in retail price, product demand, and wholesale price. Retail price does not always have a positive expected value when the manufacturer and retailer trade on the blockchain-supported e-commerce platform. Rather, the expected value is decided by the relationship between the retailer's qualification and the production cost of the counterfeit manufacturer. This means that the retail price on the blockchainsupported e-commerce platform is not always higher than that in the traditional supply chain. For a price-sensitive market, a retailer tends to trade on a blockchain-supported e-commerce platform if the retailer's qualification in the platform is lower than that in 
the traditional supply chain and the production cost of the counterfeit manufacturer in the platform is higher than that in the traditional supply chain. Otherwise, the retailer may choose to accept the threat of the counterfeit manufacturer. Moreover, the sign of the expected value of the retail price is opposite to that of the expected value of the product demand. This is because a trade-off exists between retail price and product demand. The expected value of the wholesale price is always positive, which implies that deploying blockchain technology in the supply chain always increases the wholesale price because the costs of the legitimate manufacturer in the blockchain-supported platform are higher than those in the traditional supply chain.

\section{Conclusions}

\subsection{Concluding Remarks}

As blockchain technology has characteristics of transparency, decentralization, traceability, and anonymity, it can address the product-counterfeiting problem in supply chains. This study aimed to build models that precisely evaluate the effect of blockchain technology on all participating entities within a supply chain while addressing the productcounterfeiting problem. To the best of our knowledge, no previous studies built formal analytical models to explore this aspect. Results show that the application of blockchain technology is not always beneficial to manufacturers, retailers, and customers. However, when the manufacturing cost of a legitimate manufacturer is sufficiently large, the manufacturer generates more profits using blockchain technology. Further, for a price-sensitive market, a retailer tends to trade on a blockchain-supported e-commerce platform if the retailer's qualification in the platform is lower than that in the traditional supply chain and the production cost of the counterfeit manufacturer in the platform is higher than that in the traditional supply chain. This study also shed light on supply-chain management by clarifying under which circumstances the application of blockchain technology can be beneficial for manufacturers, retailers, and customers.

\subsection{Managerial Insights}

The use of the blockchain eradicates counterfeit products, which benefits social supplychain sustainability. Customers can buy goods that are manufactured and supplied by legal firms because product information is clearly recorded on the blockchain, and illegal firms have no access to supply chains, so the blockchain-supported supply chain provides a better guarantee for human rights and fair work practices. The application of blockchain technology can eradicate counterfeit products while incurring an operating fee for the manufacturer and retailer; therefore, these firms should consider the fees involved before confirming their intention to use blockchain technology. Risk-averse retailers prefer to trade on blockchain-supported platforms to establish relationships with reliable manufacturers and obtain high-quality products. Moreover, legal products are fully protected; therefore, the manufacturer is encouraged to concentrate on product research and brand development. This is evident in the fashion and luxury industries, where manufacturers usually invest a considerable workforce and material resources in designing new products; however, counterfeit manufacturers easily imitate these products, such that it is difficult to distinguish between genuine and fake. Therefore, trading on blockchain-supported e-commerce platforms is critical in these industries. In our analyses, we showed that the consumer surplus in the blockchain-supported e-commerce platform is not always larger than that in the traditional supply chain. However, counterfeit products are a serious threat to consumers' lives, and their lawful rights and interests. To attract customers, supply chains and their firms need to offer more benefits, such as improving after-sales services and extending the warranty period of products. In addition, governments should aim to build high-quality blockchain-supported platforms for the entire industry chain, and issue relevant policies to encourage firms to trade on the platform, which is useful for creating a healthy and dynamic trading environment. 


\subsection{Future Studies}

This study focused on the fact that blockchain-supported e-commerce platforms can eradicate the product-counterfeiting problem and explored the effect of blockchain technology on all related entities. In our analyses, we only focused on the situation in which retailers and consumers are unable to distinguish between genuine and counterfeit products. However, many retailers and customers choose to buy and use counterfeit products because they may be unwilling (or unable) to pay for the more expensive genuine product, which also results in adverse effects for the legal manufacturer's profit and brand reputation. For future research, we aim to build models that include both situations to more accurately evaluate the effect of blockchain technology on all entities. Moreover, we showed that the blockchain-supported e-commerce platform charges the manufacturer and retailer an operating fee, which results in an increase in costs for both firms. Thus, there is a conflict between the platform and firms because of increased operating costs. Further studies can build models to explore the relationship between operating fees and income of the platform.

Author Contributions: Conceptualization, methodology, and software, J.J; validation, J.J. and J.C.; formal analysis, investigation, resources, data curation, and writing—original-draft preparation, J.J.; writing - review and editing, J.J. and J.C.; funding acquisition, J.C. Both authors have read and agreed to the published version of the manuscript.

Funding: This research was funded in part by the National Key R\&D Program of China, grant number 2017YFB1400700.

Acknowledgments: We thank all the participants who assisted with the research.

Conflicts of Interest: The authors declare no conflict of interest.

\section{References}

1. Chen, J.; Teng, L.; Liu, S.; Zhu, H. Anticipating regret and consumers' preferences for counterfeit luxury products. J. Bus. Res. 2015, 68, 507-515. [CrossRef]

2. Romani, S.; Gistri, G.; Pace, S. When counterfeits raise the appeal of luxury brands. Mark. Lett. 2012, 23, 807-824. [CrossRef]

3. Teodoro, J.A.R.; Pereira, H.V.; Correia, D.N.; Sena, M.M.; Piccin, E.; Augusti, R. Forensic discrimination between authentic and counterfeit perfumes using paper spray mass spectrometry and multivariate supervised classification. Anal. Methods 2017, 9, 4979-4987. [CrossRef]

4. Bansal, D.; Malla, S.; Gudala, K.; Tiwari, P. Anti-counterfeit technologies: A pharmaceutical industry perspective. Sci. Pharm. 2013, 81, 1-14. [CrossRef] [PubMed]

5. Stradley, J.; Karraker, D. The electronic part supply chain and risks of counterfeit parts in defense applications. IEEE Trans. Compon. Packag. Technol. 2006, 29, 703-705. [CrossRef]

6. Cheung, H.H.; Choi, S.H. Implementation issues in RFID-based anti-counterfeiting systems. Comput. Ind. 2011, 62, 708-718. [CrossRef]

7. Onari, M.A.; Rezaee, M.J. A fuzzy cognitive map based on Nash bargaining game for supplier selection problem: A case study on auto parts industry. Oper. Res. 2020. [CrossRef]

8. Schaede, U. Globalisation and the reorganisation of Japan's auto parts industry. Int. J. Automot. Technol. Manag. 2010, 10, 270-288. [CrossRef]

9. Dong, P.; Zhang, Y.; Gu, J.; Wu, W.; Li, M.; Yang, J.; Zhang, L.; Lü, J.; Mu, J.; Chen, L.; et al. Wogonin, an active ingredient of Chinese herb medicine Scutellaria baicalensis, inhibits the mobility and invasion of human gallbladder carcinoma GBC-SD cells by inducing the expression of maspin. J. Ethnopharmacol. 2011, 137, 1373-1380. [CrossRef]

10. Shen, C.Y.; Jiang, J.G.; Yang, L.; Wang, D.W.; Zhu, W. Anti-ageing active ingredients from herbs and nutraceuticals used in traditional Chinese medicine: Pharmacological mechanisms and implications for drug discovery. Br. J. Pharmacol. 2017, 174, 1395-1425. [CrossRef]

11. Becker, M.; Edwards, S.; Massey, R.I. Toxic chemicals in toys and children's products: Limitations of current responses and recommendations for government and industry. Environ. Sci. Technol. 2010, 44, 7986-7991. [CrossRef] [PubMed]

12. Korfali, S.I.; Sabra, R.; Jurdi, M.; Taleb, R.I. Assessment of toxic metals and phthalates in children's toys and clays. Arch. Environ. Contam. Toxicol. 2013, 65, 368-381. [CrossRef]

13. Roberts, C.M. Radio frequency identification (RFID). Comput. Secur. 2006, 25, 18-26. [CrossRef]

14. Romero, H.P.; Remley, K.A.; Williams, D.F; Wang, C.M. Electromagnetic measurements for counterfeit detection of radio frequency identification cards. IEEE Trans. Microw. Theory Tech. 2009, 57, 1383-1387. [CrossRef] 
15. Xie, R.; Hong, C.; Zhu, S.; Tao, D. Anti-counterfeiting digital watermarking algorithm for printed QR barcode. Neurocomputing 2015, 167, 625-635. [CrossRef]

16. Wicks, A.M.; Visich, J.K.; Li, S. Radio frequency identification applications in hospital environments. Hosp. Top. 2006, 84, 3-9. [CrossRef]

17. Ye, D.; Zhang, T.Y.; Guo, G. Stochastic coding detection scheme in cyber-physical systems against replay attack. Inf. Sci. 2019, 481, 432-444. [CrossRef]

18. Callegati, F.; Cerroni, W.; Ramilli, M. Man-in-the-Middle Attack to the HTTPS Protocol. IEEE Secur. Priv. 2009, 7, 78-81. [CrossRef]

19. Saberi, S.; Kouhizadeh, M.; Sarkis, J.; Shen, L. Blockchain technology and its relationships to sustainable supply chain management. Int. J. Prod. Res. 2019, 57, 2117-2135. [CrossRef]

20. Francisco, K.; Swanson, D. The supply chain has no clothes: Technology adoption of blockchain for supply chain transparency. Logistics 2018, 2, 2. [CrossRef]

21. Ko, T.; Lee, J.; Ryu, D. Blockchain technology and manufacturing industry: Real-time transparency and cost savings. Sustainability 2018, 10, 4274. [CrossRef]

22. Queiroz, M.M.; Wamba, S.F. Blockchain adoption challenges in supply chain: An empirical investigation of the main drivers in India and the USA. Int. J. Inf. Manag. 2019, 46, 70-82. [CrossRef]

23. Clauson, K.A.; Breeden, E.A.; Davidson, C.; Mackey, T.K. Leveraging blockchain technology to enhance supply chain management in healthcare: An exploration of challenges and opportunities in the health supply chain. Blockchain Healthc. Today 2018, 1, 1-12.

24. Azzi, R.; Chamoun, R.K.; Sokhn, M. The power of a blockchain-based supply chain. Comput. Ind. Eng. 2019, 135, 582-592. [CrossRef]

25. Kamilaris, A.; Fonts, A.; Prenafeta-Bold v́, F.X. The rise of blockchain technology in agriculture and food supply chains. Trends Food Sci. Technol. 2019, 91, 640-652. [CrossRef]

26. Singh, M.; Kim, S. Branch based blockchain technology in intelligent vehicle. Comput. Netw. 2018, 145, 219-231. [CrossRef]

27. Alazab, M.; Alhyari, S.; Awajan, A.; Abdallah, A.B. Blockchain technology in supply chain management: An empirical study of the factors affecting user adoption/acceptance. Clust. Comput. 2021, 24, 83-101. [CrossRef]

28. Ying, W.; Jia, S.; Du, W. Digital enablement of blockchain: Evidence from HNA group. Int. J. Inf. Manag. 2018, 39, 1-4. [CrossRef]

29. Liu, C.; Xiao, Y.; Javangula, V.; Hu, Q.; Wang, S.; Cheng, X. NormaChain: A blockchain-based normalized autonomous transaction settlement system for IoT-based E-commerce. IEEE Internet Things J. 2018, 6, 4680-4693. [CrossRef]

30. Scekic, O.; Nastic, S.; Dustdar, S. Blockchain-supported smart city platform for social value co-creation and exchange. IEEE Internet Comput. 2018, 23, 19-28. [CrossRef]

31. Albrecht, C.C.; Dean, D.L.; Hansen, J.V. Marketplace and technology standards for B2B e-commerce: Progress, challenges, and the state of the art. Inf. Manag. 2005, 42, 865-875. [CrossRef]

32. Xu, S.X.; Cheng, M.; Huang, G.Q. Efficient intermodal transportation auctions for B2B e-commerce logistics with transaction costs. Transp. Res. Part B Methodol. 2015, 80, 322-337. [CrossRef]

33. Padmannavar, S.S. A review on E-Commerce empowering Women's. Int. J. Comput. Sci. Telecommun. $2011,2,74-78$.

34. Sutton, S.G.; Khazanchi, D.; Hampton, C.; Arnold, V. Risk analysis in extended enterprise environments: Identification of critical risk factors in B2B e-commerce relationships. J. Assoc. Inf. Syst. 2008, 9, 151-174. [CrossRef]

35. Wu, T.; Liu, X.; Qin, J. A linguistic solution for double large-scale group decision-making in E-commerce. Comput. Ind. Eng. 2018, 116, 97-112. [CrossRef]

36. Zhu, Q.; Dou, Y. Evolutionary game model between governments and core enterprises in greening supply chains. Syst. Eng. Theory Pract. 2007, 27, 85-89. [CrossRef]

37. Mei, Q.; Zhou, Q.; Liu, S.; Wang, Q. A Safety Signaling Game for Small and Medium-sized Manufacturing Enterprises in the Supply Chain. Int. J. Inf. Syst. Supply Chain Manag. (IJISSCM) 2020, 13, 118-135. [CrossRef]

38. Fricke, D.; Lux, T. Core-periphery structure in the overnight money market: Evidence from the e-mid trading platform. Comput. Econ. 2015, 45, 359-395. [CrossRef]

39. Zhang, M.; Pratap, S.; Huang, G.Q.; Zhao, Z. Optimal collaborative transportation service trading in B2B e-commerce logistics. Int. J. Prod. Res. 2017, 55, 5485-5501. [CrossRef]

40. Huang, Y.; Chai, Y.; Liu, Y.; Shen, J. Architecture of next-generation e-commerce platform. Tsinghua Sci. Technol. 2018, 24, 18-29. [CrossRef]

41. Zheng, Z.; Xie, S.; Dai, H.N.; Chen, X.; Wang, H. Blockchain challenges and opportunities: A survey. Int. J. Web Grid Serv. 2018, 14, 352-375. [CrossRef]

42. Dinh, T.T.A.; Liu, R.; Zhang, M.; Chen, G.; Ooi, B.C.; Wang, J. Untangling blockchain: A data processing view of blockchain systems. IEEE Trans. Knowl. Data Eng. 2018, 30, 1366-1385. [CrossRef]

43. Secinaro, S.; Calandra, D.; Biancone, P. Blockchain, trust, and trust accounting: Can blockchain technology substitute trust created by intermediaries in trust accounting A theoretical examination. Int. J. Manag. Pract. 2021, 14, 129-145. [CrossRef]

44. Yuan, R.; Xia, Y.B.; Chen, H.B.; Zang, B.Y.; Xie, J. Shadoweth: Private smart contract on public blockchain. J. Comput. Sci. Technol. 2018, 33, 542-556. [CrossRef]

45. Tang, H.; Shi, Y.; Dong, P. Public blockchain evaluation using entropy and TOPSIS. Expert Syst. Appl. 2019, 117, 204-210. [CrossRef] 
46. Dorri, A.; Luo, F.; Kanhere, S.S.; Jurdak, R.; Dong, Z.Y. SPB: A secure private blockchain-based solution for distributed energy trading. IEEE Commun. Mag. 2019, 57, 120-126. [CrossRef]

47. Yang, R.; Wakefield, R.; Lyu, S.; Jayasuriya, S.; Han, F.; Yi, X.; Yang, X.; Amarasinghe, G.; Chen, S. Public and private blockchain in construction business process and information integration. Autom. Constr. 2020, 118, 103276. [CrossRef]

48. Li, Z.; Kang, J.; Yu, R.; Ye, D.; Deng, Q.; Zhang, Y. Consortium blockchain for secure energy trading in industrial internet of things. IEEE Trans. Ind. Inform. 2017, 14, 3690-3700. [CrossRef]

49. Kang, J.; Xiong, Z.; Niyato, D.; Wang, P.; Ye, D.; Kim, D.I. Incentivizing consensus propagation in proof-of-stake based consortium blockchain networks. IEEE Wirel. Commun. Lett. 2018, 8, 157-160. [CrossRef]

50. Nakamoto, S. Bitcoin: A Peer-to-Peer Electronic Cash System. 2008. Available online: https://bitcoin.org/bitcoin.pdf (accessed on 11 April 2021).

51. Chen, J.; Cai, T.; He, W.; Chen, L.; Zhao, G.; Zou, W.; Guo, L. A Blockchain-Driven Supply Chain Finance Application for Auto Retail Industry. Entropy 2020, 22, 95. [CrossRef]

52. Babich, V.; Tang, C.S. Managing opportunistic supplier product adulteration: Deferred payments, inspection, and combined mechanisms. Manuf. Serv. Oper. Manag. 2012, 14, 301-314. [CrossRef]

53. Choi, T.M. Blockchain-technology-supported platforms for diamond authentication and certification in luxury supply chains. Transp. Res. Part E Logist. Transp. Rev. 2019, 128, 17-29. [CrossRef]

54. Cai, Y.J.; Choi, T.M.; Zhang, J. Platform supported supply chain operations in the blockchain era: Supply contracting and moral hazards. Decis. Sci. 2020, 15, 21-35. [CrossRef]

55. Song, Q.; Chen, Y.; Zhong, Y.; Lan, K.; Fong, S.; Tang, R. A supply-chain system framework based on internet of things using Blockchain technology. ACM Trans. Internet Technol. 2021, 21, 1-24. [CrossRef]

56. Radón, A. Counterfeit luxury goods online: An investigation of consumer perceptions. Int. J. Mark. Stud. 2012, 4, 74-81.

57. Agarwal, S.; Panwar, S. Consumer Orientation Towards Counterfeit Fashion Products: A Qualitative Analysis. IUP J. Brand Manag. 2016, 13, 34-39.

58. Alzahrani, N.; Bulusu, N. Block-supply chain: A new anti-counterfeiting supply chain using NFC and blockchain. In Proceedings of the 1st Workshop on Cryptocurrencies and Blockchains for Distributed Systems, Munich, Germany, 15 June 2018; pp. 30-35.

59. Kumar, R.; Tripathi, R. Traceability of counterfeit medicine supply chain through Blockchain. In Proceedings of the 2019 11th International Conference on Communication Systems \& Networks (COMSNETS), Bengaluru, India, 7-11 January 2019; IEEE: New York, NY, USA, 2019; pp. 568-570.

60. Modgil, S.; Sonwaney, V. Planning the application of blockchain technology in identification of counterfeit products: Sectorial prioritization. IFAC-PapersOnLine 2019, 52, 1-5. [CrossRef] 